\title{
THE EFFECT OF SPECIAL EXERCISES USING SOME TOOLS TO DEVELOP THE DISTINCTIVE SPEED FOR THE ARMS AND LEGS IN $\approx \times 3$ BASKETBALL FOR PLAYERS AGES (UNDER 18 YEARS)
}

\author{
DOAA HABEEB TALAB, Prof. Dr. MUHANAD ABD ALSATAR \\ University of Baghdad / College of Physical Education and Sports Sciences
}

DOI: $10.37648 / \mathrm{ijrssh} . v 10 \mathrm{i} 02.036$

Received: $20^{\text {th }}$ March, 2020; Accepted: $24^{\text {th }}$ April, 2020; Published: $13^{\text {th }}$ May, 2020

\begin{abstract} experimental group that folded the special exercises.

INTRODUCTION

We cannot lose sight of sporting progress in various sports, including the game of basketball at the Arab, continental and global levels. Iraq is one of the countries that seeks towards achieving that progress. In order to keep pace with this progress, a deep view of the nature of play during the games in the game of basketball for ( $\mathbf{D S}$ ) that It is characterized by the speed and the constant change of the playing rhythm, whether it is in defense or attack, as well as in fast and changing game movements.
\end{abstract}

The study aimed to prepare special exercises for using some auxiliary tools to develop the distinctive speed for the arms and legs in $\mathbf{A B}$ basketball for the Zima Sports Club players in Sulaymaniyah, in addition to identifying the effect of the exercises for using some auxiliary tools to develop the distinctive speed of the arms and legs in $\mathbf{A}$ basketball for the research sample, The researchers adopted the experimental approach, and the number of the research sample reached (6) players for each experimental and control group, and the researchers applied their main experiment using special exercises with some auxiliary tools by (4) training units during the week for a period of (8) Sale, and the results of the study indicated a significant effect on the results of the force-tested speed of arms and legs between the two groups and in favor of the

Keywords: Special exercises, auxiliary tools, the distinctive speed of arms and legs, basketball to $\mathbf{A B}$

And the basketball game for $(\mathbf{A})$ requires its players to have highly efficient physical abilities, especially the strength marked by the speed of the arms and legs, so using the basic skills of the game, whether they are offensive or defensive skills, may be appropriate to them from attributes or physical abilities that cannot be available unless planning training for them is based on scientific planning On the specificity of training for the game, which requires emphasis on its development for its apparent impact in the application and integration of the physical, skill and planning aspect, and the changing, fast, sudden and fast rhythm situations that characterize this 
game require developing the physical capabilities of the player's offensive movements and the Defensive and accurate follow-up with the ball or without a ball in line with the changing situations faced by the player inside the stadium, which needs a high level of physical abilities represented by the strength marked by the speed of the arms and legs, where the components of each physical ability appear clearly during skill performance and accuracy of follow-up.

Hence the importance of the research through preparing special exercises using some tools to develop the distinctive speed for the arms and legs and using them within the limits of the measurements of the basketball field for the research. Attention must be paid to the fundamentals of training numbers, and it is necessary that these special exercises include a large part of the components of the real matches through which the players reach the high achievement, especially when they are put under pressure from competition.

The research problem emerged through the researchers 'observation of the novelty of the game and the short training of the players and the lack of an integrated training curriculum for the game that led to the weakness of some physical capabilities of the players, including the strength marked by the speed of the arms and legs, and from here came the research problem and the researchers' desire to develop special exercises that will undoubtedly lead to building a nervous consensus Muscle in the player to meet the requirements of the game $\mathbf{A} \boldsymbol{\beta}$, so the two researchers decided to go into this problem and try to solve it by applying these special exercises.

A study which is a previous study related to the subject of the study as a study (Dr.paul, 2017) showed that the use of strength and speed training per se improves the physical ability of basketball players to $\mathbf{A} \boldsymbol{\mathcal { Z }}$, and that the integration of speed training with strength training together will help significantly speed and quality of movement Inside the basketball court for $\mathbf{A} \mathbf{S}$, and in a Table (1) study (Doaa, 2014), the results showed that the special exercises prepared have a positive effect on the development of the strength marked by the speed of the arms and legs, and also the effectiveness of the diversity of the exercises contributed to the development of strength and speed among the research sample, and in the study (Omar, 2015) shows Through the results of the study, the experimental group used the Exercises for the use of assistive training tools. A positive effect in developing the physical abilities of the speed-strong strength of the arms and legs of basketball players $\mathbf{A} \boldsymbol{B}$. As the purpose of the study was:

- Prepare special exercises using some aids to develop the distinctive speed for the arms and legs of the basketball for players $\mathbf{A} \boldsymbol{B}$.

$=-$ Learn about the effect of exercises on using some auxiliary tools to develop the distinctive speed for the arms and legs of the basketball $\mathbf{E} \boldsymbol{\mathcal { B }}$ for the research sample.

\section{MATERIALS AND METHODS:}

In their research, the researchers used the experimental approach to design the two equivalence groups with pre and post tests, as the research community, represented by Zema sports club players in Sulaimaniyah, as the researchers made a deliberate choice for the research community consisting of (Kurdistan region club teams for young women), as the research sample reached (12) players (6) Experimental and (6) control subjects, representing $(24.48 \%)$ of the total population, while the sample of the exploratory experiment (3) was from outside the research sample.

The researchers used parity in the force marked by the speed of the arms and legs between the two research groups, as shown in the table below.

\begin{tabular}{|c|c|c|c|c|c|c|c|}
\hline \multirow[t]{2}{*}{ Sig value } & \multirow{2}{*}{$\begin{array}{ll}\text { Calculated } & \mathrm{t} \\
\text { value } & \end{array}$} & \multicolumn{2}{|c|}{ Control group } & \multicolumn{2}{|c|}{ Experimental group } & \multirow[t]{2}{*}{ Measurement unit } & \multirow[t]{2}{*}{ Variables } \\
\hline & & $\begin{array}{l}\text { standard } \\
\text { deviation }\end{array}$ & $\begin{array}{l}\text { Arithmetic } \\
\text { mean }\end{array}$ & $\begin{array}{l}\text { standard } \\
\text { deviation }\end{array}$ & $\begin{array}{l}\text { Arithmetic } \\
\text { mean }\end{array}$ & & \\
\hline 0.184 & 1.426 & 3.868 & 8.166 & 1.861 & 10.666 & Repeats & $\begin{array}{l}\text { Distinguished force } \\
\text { at the speed of arms }\end{array}$ \\
\hline 0.093 & 1.859 & 1.480 & 8.340 & 1.347 & 10.393 & distance & $\begin{array}{l}\text { Distinguished } \\
\text { strength at the speec } \\
\text { of the feet }\end{array}$ \\
\hline
\end{tabular}


As for the scientific foundations of the strength and speed tests for the arms and legs, the researchers followed:

Verify the test

The two researchers used self-confidence by calculating the square root of the test stability coefficient by the following equation (coefficient of self-confidence $=$ coefficient of stability)

Stability of the test

The stability factor was calculated by applying the tests to a sample consisting of (4) female players from the parent community on Monday 8/7/2019, then the test was repeated on Saturday 13/7/2019, i.e. with an interval of 5 days on The same group and under the same conditions and after obtaining data for the two tests were statistically processed by finding the simple correlation coefficient Pearson between the first and second test as the results showed that the correlation coefficient values are high and this means that all the tests used in the research have a high degree of stability as shown in the table (2)

Test objectivity

In order for researchers to be free from intolerance and bias in the results of the two testers, he resorted to extracting the objective value of the tests by calculating the correlation coefficient between two measurement scores for two assessors, as they recorded the test results for all (4) and for all the tests simultaneously and separately, in that On Monday (7/7/2019) during the implementation of the first pilot experiment, after which data was collected and statistically processed by Pearson Simple Correlation Coefficient, as the results were of high objectivity and for all tests.

Table (2)

\begin{tabular}{|l|l|l|l|l|}
\hline $\begin{array}{l}\text { Objectivity of } \\
\text { the test }\end{array}$ & Testify & $\begin{array}{l}\text { Stability } \\
\text { of the test }\end{array}$ & $\begin{array}{l}\text { measruing } \\
\text { unit }\end{array}$ & Tests \\
\hline $\mathbf{0 . 9 8 8}$ & $\mathbf{0 . 9 9 5}$ & $\mathbf{0 . 9 9 1}$ & Repeats & $\begin{array}{l}\text { The distinctive strength of the arms of } \\
\text { Chinaw 10 t }\end{array}$ \\
\hline $\mathbf{0 . 9 5 9}$ & $\mathbf{0 . 9 8 6}$ & $\mathbf{0 . 9 7 4}$ & distance & $\begin{array}{l}\text { The distinctive strength of the partridge's } \\
\text { feet 3 times }\end{array}$ \\
\hline
\end{tabular}

After that, the two researchers conducted the pre-test of the research sample by applying the tribal tests to the experimental and control groups, as the physical abilities were conducted on (Wednesday) (17/7/2019) at (3:30 pm) Application of training modules for the study topic:

The researchers have prepared training units using special exercises with some training tools to help develop the physical abilities of the strength marked by the speed of the arms and legs of the research sample, the curriculum starts from 20/7/2019 - 9/13/2019, and the number of training units per week (4) Units, training days (Saturday - Monday - Wednesday - Friday), the duration of exercises (8) weeks, the total number of training units (32) units, was used the method of training young highintensity.

Some of the auxiliary tools were used by the researchers with special exercises, namely:

Perforated cone perforator + stick (Cone): They are plastic cones and take different shapes and heights are lightweight used in most sporting activities and according to the type and goal of the exercise as it can be moved, installed and moved easily with ease.

Hurdles Jump: It is a tube made of lightweight plastic, the shape of which is similar to the ones used in running but it is small in size and with three different heights (10-20-30) $\mathrm{cm}$ for easy carrying and transporting according to the type of exercise. The contraindications are used in strength training. Fitness and balance in most individual and team sports.

Training Ladder: It consists of two parallel belt made of durable fabric in many colors. The length of the ladder is $(4.20 \mathrm{~m})$ and its width $(50 \mathrm{~cm})$. It contains (12) pieces of plastic, yellow or green, adjustable in order to control the distance between the square. And another according to the specificity of the exercise and according to the measurement of the players 'feet. The agility ladder is used in fitness training, muscular compatibility and balance.

Color Rings: 12 rings of four different colors with a diameter $(40 \mathrm{~cm})$, made of hard plastic (PVC), which have a flat design, which makes it ideal and not hindered 
(IJRSSH) 2020, Vol. No. 10, Issue No. II, Apr-Jun

e-ISSN: 2249-4642, p-ISSN: 2454-4671

for use on surfaces in the external squares and internal halls, and is used in fitness and balance exercises

Compatibility and accuracy.

illustrations of some of the utilities used in the research
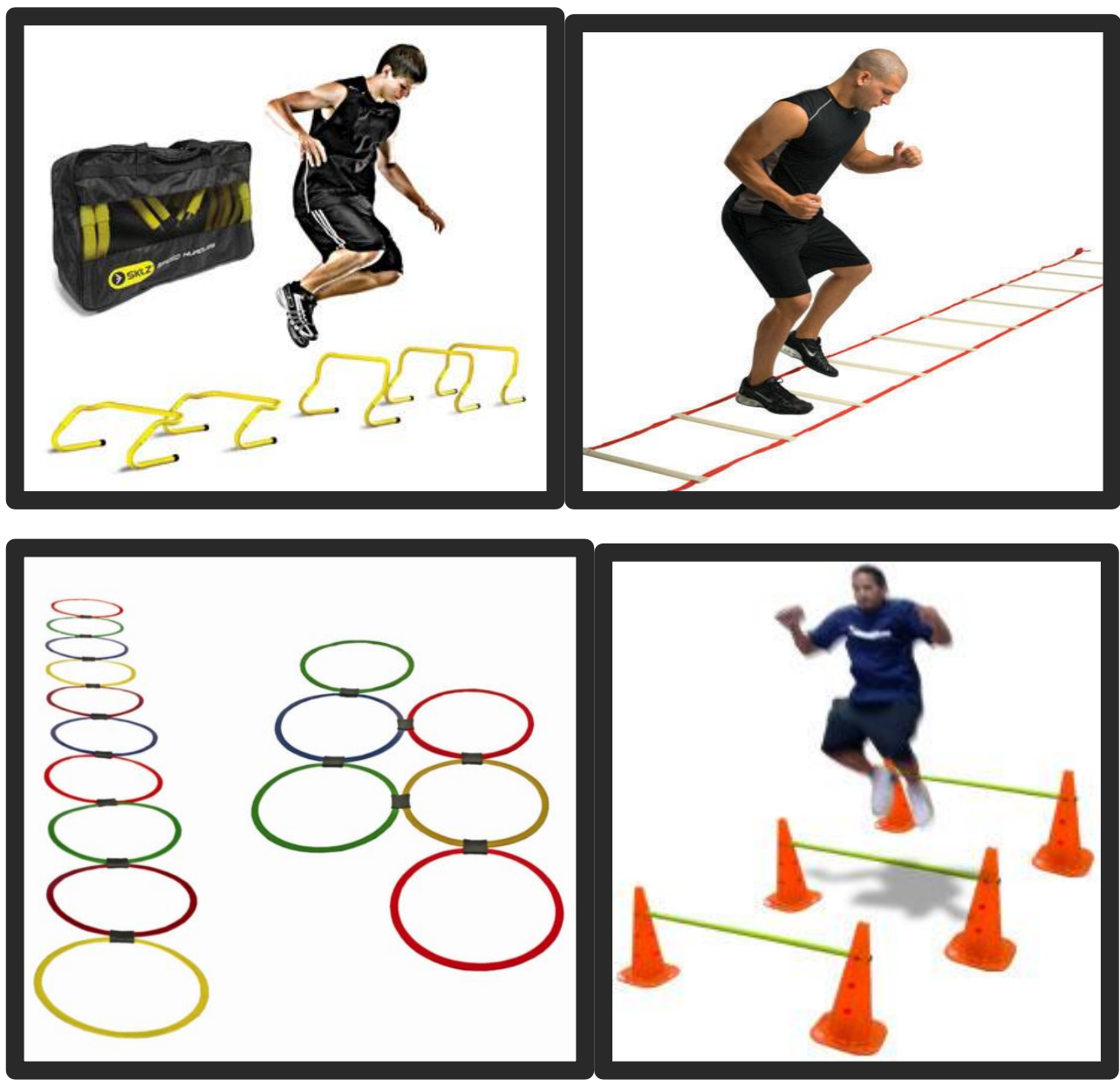

After that, the two researchers conducted the post-test (7/19/2014) after the last two training units at (10) in the morning and in the hall of Zema Sports Club in Sulaimaniyah, and accompanied by the assistant work, under the same temporal and spatial conditions that were applied in the exploratory experiment and the same conditions for implementing the test .

RESULT AND DISCUSSION:

Table (3)

Results of the pre- and post-tests for the two groups

\begin{tabular}{|l|l|l|l|l|l|l|l|l|l|}
\hline indication & sig & $\begin{array}{l}\text { Calculated } \\
\text { value }\end{array}$ & & \begin{tabular}{l} 
The test is after \\
\cline { 3 - 8 }
\end{tabular} & $\begin{array}{l}\text { standard } \\
\text { deviation }\end{array}$ & $\begin{array}{l}\text { Arithmetic } \\
\text { mean }\end{array}$ & $\begin{array}{l}\text { The test is before } \\
\text { standard } \\
\text { deviation }\end{array}$ & $\begin{array}{l}\text { Arithmetic } \\
\text { mean }\end{array}$ & unit \\
\hline moral & 0.005 & 4.719 & 0.894 & 13 & 1.861 & 10.666 & $\begin{array}{l}\text { The number } \\
\text { of times }\end{array}$ & $\begin{array}{l}\text { Distinctive force } \\
\text { of } \\
\text { (Experimental) } \\
\text { arms }\end{array}$ \\
\hline moral & 0.020 & 3.371 & 3.060 & 9.833 & 3.868 & 8.166 & The number & Distinctive force \\
\hline
\end{tabular}




\begin{tabular}{|l|l|l|l|l|l|l|l|l|}
\hline & & & & & & & of times & $\begin{array}{l}\text { of arms } \\
\text { (Adjustable) }\end{array}$ \\
\hline moral & 0.003 & 5.426 & 1.040 & 11.556 & 1.347 & 10.393 & $\begin{array}{l}\text { Distinguished } \\
\text { Force at Feet } \\
\text { Speed } \\
\text { (Experimental) }\end{array}$ \\
\hline moral & 0.006 & 4.560 & 1.391 & 9.028 & 1.408 & 8.340 & distance & $\begin{array}{l}\text { Distinctive force } \\
\text { at feet speed } \\
\text { (Adjustable) }\end{array}$ \\
\hline
\end{tabular}

Table (4)

Results of the two-dimensional tests for the two groups

\begin{tabular}{|l|l|l|l|l|l|l|l|}
\hline SIG & \multirow{2}{*}{$\begin{array}{l}\text { Calculated T } \\
\text { value }\end{array}$} & \multicolumn{2}{|l|}{ Control group } & \multicolumn{2}{|l|}{ Experimental group } & measruing unit & Variables \\
\cline { 3 - 7 } & $\begin{array}{l}\text { standard } \\
\text { deviation }\end{array}$ & $\begin{array}{l}\text { Arithmetic } \\
\text { mean }\end{array}$ & $\begin{array}{l}\text { standard } \\
\text { deviation }\end{array}$ & $\begin{array}{l}\text { Arithmetic } \\
\text { mean }\end{array}$ & & \\
\hline $\mathbf{0 . 0 3 5}$ & $\mathbf{2 . 4 3 3}$ & 3.060 & 9.833 & 0.894 & 13 & How often & $\begin{array}{l}\text { Distinguished force } \\
\text { at the speed of arms }\end{array}$ \\
\hline $\mathbf{0 . 0 0 5}$ & $\mathbf{3 . 5 6 4}$ & 1.391 & 9.028 & 1.040 & 11.556 & distance & $\begin{array}{l}\text { Distinguished } \\
\text { strength at the } \\
\text { speed of the feet }\end{array}$ \\
\hline
\end{tabular}

By presenting the results in the above table, which shows the existence of significant differences between the tribal and posttest tests, and for both the experimental and experimental groups in the test of the distinctive velocity of the arms and legs, but the superiority in them are tests in favor of the experimental, as the researchers attribute this superiority to the test of the distinctive velocity of the arms (El-Shennaw 10) D) To the exercises for the use of assistive devices, the reason for the development in the results of the physical testing of the two arms is due to the positive effect of the applied approach and its good organization, as the increase in the number of iterations in the bending and stretching of the arms (Shinaw) test in (10) seconds indicates that $\mathrm{He}$ developed the characteristic strength characteristic of speed, as the performance of the exercises was applied during a period of (10) seconds, in order to maintain the development of this characteristic without entering into the development of other characteristics, and the development of the strength characteristic of speed for the arms is due to the use of exercises with medical balls and appropriate their weights in terms of The ages and capabilities of the players, and the basketball player needs strength and speed to try to succeed in linking multiple movement skills in one frame.

As the movement with different speed and strength and sudden change of direction had a great role in increasing and developing the force distinguished by the speed of the players of the experimental group through special exercises, which was characterized by its nature close to the actual playing conditions, and this is confirmed by (Raisan, 1998) "the various means in training The dynamic, which provides a varied effect on the nervous system and also helps in the mixing of strengths. "Therefore, the two researchers have achieved the goal of the research with regard to developing the distinctive speed of arms for basketball players. As for the partridge test three times, the researchers attribute the reason for the development to the effect of special exercises using the aids developed by the researchers for the special experimental group represented by (training ladder exercises and jumping on colored circles with one or both legs on the ground and jumping exercises on perforated characters as well as cones and inhibitors), As the player who performs the exercise on one leg, the entire body weight will dominate that man, that is, the resistance to it increases, which leads to the development of the muscle 
groups of that man. And when the player performs the same exercise that was performed by one man with two legs together, and The body will be distributed among the two men, and thus the resistance will decrease and then the development will be less than the previous one, and this is what he indicated to (Abd Ali Nassif, 1988) "The level of athletic achievement rises rapidly during the use of new exercises that the athlete is not accustomed to and can bear special doses." (Muhammad , 2007) Also, when the player performs this same exercise, but alternately, both men will take a break from one step to the other, and thus the development is less, as the exercises were characterized by the increase in the number of repetitions in line with the ability of the players.

\section{REFERENCES:}

- D. m. (2017). THE PHYSICAL AND PHYSIOLOGICAL CHARACTERISTICS OF 3 ON3 RESULTS OF MEDICAL STUDY \&SCIENTIFIC TEST. international basketball federation, 5.

schmid and lea. (2005). motor control and learning il homan ad kintics. -

- Habib asked a supplication. (2014). Special exercises to develop some physical abilities and their impact on some basic skills of basketball for $3 \times 3$ for players under 18 years of age. Master Thesis, University of Baghdad, College of Physical Education and Sports Science., 2, 3. Baghdad.

- Khreisan Resan. (1998). General theories in sports training. (Al-Shorouk Press, Editor) Jordan.

- Omar, S. H. (2015). Exercises using auxiliary tools to develop special muscle strength and its effect on some complex skills of basketball for $3 \times 3$ ages under 18 years. Master Thesis, University of Babylon, College of Physical Education and Sports Science.

- Qassem Hassan Hussein Abdul Ali Nassif. (1988). Principles of sports training. Baghdad: Higher Education Press.

- Muhammad, z. (2007). The effect of a training curriculum using two different methods to develop the jumping strength of the two men and its relationship to the accuracy of the overwhelming skill of hitting young volleyball players. Master Thesis, University of Baghdad, College of Physical Education and Sports Science.

- Khion Expresses. (2010). Kinetic learning between principle and application (volume i 2). Baghdad: The Good Word Press. 